\title{
SUGAR NUCLEOTIDE TRANSFERASES IN ESCHERICHIA COLI LIPOPOLYSACCHARIDE BIOSYNTHESIS ${ }^{1}$ \\ Ronald D. Edstrom ${ }^{2,3}$ and Edward C. Heath ${ }^{2}$ \\ Rackham Arthritis Research Unit and Department of Microbiology The University of Michigan, Ann Arbor \\ and \\ Department of Physiological Chemistry \\ The Johns Hopkins School of Medicine, Baltimore
}

Received June 22, 1964

The cell wall lipopolysaccharide (LPS) of E. coli 0111 is a complex polymer which contains fatty acids, phosphorus, hexosamine, 3-deoxy-octulosonate (KDO) (Heath and Ghalambor, 1963), heptose, glucose, galactose and colitose (3,6 dideoxyL-xylohexose). A mutant of this organism, E. coli J-5 (Heath and Elbein, 1962), lacks the enzyme UDP-galactose-4-epimerase. When the organism is grown in the absence of galactose, an incomplete LPS is formed which lacks galactose and colitose and contains reduced amounts of glucose and $\mathrm{N}$-acetyl glucosamine. This paper presents evidence for the sequential enzymatic transfer of galactose, glucose, $\mathrm{N}$-acetyl glucosamine and colitose (from their respective nucleotide derivatives) to the deficient LPS of E. coli J-5. Further, evidence is presented indicating that the transfer of KDO, from cytidine monophosphate-KDO $(C M P-K D O)$ is catalyzed by crude extracts from either the wild-type organism or the mutant; the acceptor for this transferase is a fragment of LPS obtained by chemical degradation.

Materials and Methods--- All compounds were obtained from commercial sources unless noted below. KDO-1-C $\mathrm{C}^{14}\left(3 \times 10^{6} \mathrm{cpm} / \mu\right.$ mole) was prepared enzymatically (Ghalambor and Heath, 1963b). CMP-KDO- J-C $\mathrm{C}^{14}$ was generated just before use from CTP and KDO (Ghalambor and Heath, 1963a). GDP-mannose-C ${ }^{14}\left(7.8 \times 10^{5} \mathrm{cpm} / \mu\right.$ mole) was prepared from mannose-U-C $\mathrm{C}^{14}$ with extracts of a mutant of Salmonella typhimurium ${ }^{4}$. GDP-colitose-C $C^{14}$ (GDP-Col, $7.8 \times 10^{5} \mathrm{cpm} / \mu$ mole) was prepared from GDP-mannose as described previously (Heath and Elbein, 1962).

1 Supported by grants from the National Institutes of Health: AM-083 18 and AM-06278.

2 Present address: Department of Physiological Chemistry, The Johns Hopkins School of Medicine.

3 U. S. P. H. S. postdoctoral fellow.

4 We would like to thank Dr. S. Rosen, Department of Molecular Biology, Albert Einstein School of Medicine, New York, N. Y. for providing this organism and details of preparation of GDP-mannose prior to the publication of his results. 
UDP-galactose- $C^{14}$ (UDP-Gal, $1 \times 10^{6} \mathrm{cpm} / \mu$ mole) was prepared by the method of Wiesmeyer and Jordan (1961) with use of E. coli J-5. UDP-glucose-C ${ }^{14}$ (UDP-Glc, $1 \times 10^{6} \mathrm{cpm} / \mu \mathrm{mole}$ ) and UDP-galactose were chemically prepared (Roseman et al., 1961). UDP-N-acetyl glucosamine- $C^{14}$ (acetyl labeled) (UDP-GlcNAc, $8.7 \times 10^{5}$ $\mathrm{cpm} / \mu \mathrm{mole}$ ) was a gift of Mr. Jack Distler of the Rackham Arthritis Research Unit. Paper electrophoresis was done on Whatman No. $3 \mathrm{MM}$ paper at 40 to $60 \mathrm{volts} / \mathrm{cm}$ in either $0.05 \mathrm{M}$ sodium borate, $0.06 \mathrm{M}$ pyridinium acetate, $\mathrm{pH} 4.6$, or $0.1 \mathrm{M}$ sodium molybdate, pH 5.0 (Bourne et al., 1959). Paper chromatographic (Whatman No. 1) solvents used were as follows: I. butane-l-ol:pyridine:0.1 N HCl (5:3:2); Il. propane-2-ol:water (7:3); III. propane-2-ol:water (8:2); IV. ethyl acetate:acetic acid:water (upper phase of 3:1:3 mixture). Sugars were detected with alkaline silver nitrate (Trevelyan et al., 1950); KDO by the method of Warren (1960). Phosphorus was determined by the method of Chen et al., (1956), hexosamine by the Boas (1953) procedure, fatty acids by the Duncombe method (1963) using $\beta$-hydroxy lauric acid as the standard 5 , and KDO by the Weissbach and Hurwitz (1959) modification of the method of Waravdekar and Saslaw (1959). E. coli 0111 or J-5 were grown in shake cultures on Trypticase Soy broth ${ }^{6}$ until the early log phase was reached. Cells were disrupted by sonic oscillation. LPS was prepared by phenol extraction (Westphal et al., 1952).

Polysaccharide biosynthesis--- The washed, 12,000-40,000 Xg particulate fraction of extracts of E. coli J-5 contained both the deficient LPS and the glycosyl transferase activities to be described. When this cell fraction was incubated with various combinations of labeled and unlabeled sugar nucleotides, the results shown in Table I were obtained. These data suggest that the various sugar constituents of the polysaccharide are transferred to the polymer sequentially, as follows: galactose, glucose, $\mathrm{N}$-acetyl glucosamine, and colitose.

LPS was isolated from incubation mixtures by Pronase digestion, ethanol precipitation and magnesium ion precipitation (Osborn et al., 1962). The purified LPS preparations (which contained 70 to $90 \%$ of the $\mathrm{C}^{14}$ originally present in the washed ethanol precipitates) were hydrolyzed in $2 \mathrm{~N} \mathrm{H}_{2} \mathrm{SO}_{4}$ for 2 hours at $100^{\circ}$. The liberated radioactive sugars were characterized by paper chromatography, paper electrophoresis (in borate buffer) and as follows: glucose by glucose oxidase, and galactose by galactose dehydrogenase (Doudoroff, 1962). The conditions of hydrolysis necessary to cleave the

5 We would like to thank Dr. W. J. Lennarz for this compound.
Baltimore Biological Laboratories, Baltimore, Maryland. 
hexosaminyl bond also caused deacetylation and thus prevented characterization of the acetyl labeled $\mathrm{N}$-acetyl glucosamine.

Table 1

\begin{tabular}{|c|c|c|c|}
\hline $\mathrm{C}^{14}$ SUBSTRATE & ADDITION & mpmoles INCORPORATED & $\begin{array}{l}\text { MOLAR } \\
\text { RATIO** }\end{array}$ \\
\hline UDP-Gal* & None & 10.2 & 15 \\
\hline UDP-Gal & UDP-GIc & 10.0 & \\
\hline UDP-Gle & None & 0.8 & \\
\hline UDP-GIc & UDP-Gal & 5.5 & 7.9 \\
\hline UDP-GIcNAc & None & 0.7 & \\
\hline UDP-GICNAc & UDP-Gal or UDP-Gle & 0.9 & \\
\hline UDP-GIcNAc & UDP-Gal and UDP-Glc & 3.3 & 4.7 \\
\hline GDP-Col & None & 0.1 & \\
\hline GDP-Col & UDP-Gal and UDP-GIc & 0.1 & \\
\hline GDP-Col & -Gal, UDP-Glc and UDP-GlcNAc & 1.0 & 1.4 \\
\hline
\end{tabular}

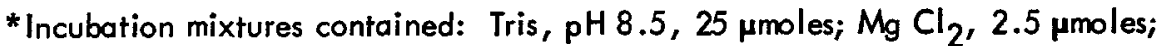
chloramphenicol, $25 \mu \mathrm{g}$; sugar nucleotide, 0.1 mole; enzyme particulate, $0.4 \mathrm{mg}$ protein. Final volume was $0.25 \mathrm{ml}$. The mixtures were incubated at $37^{\circ}$ for 2 hours. The reactions were stopped by the addition of $0.5 \mathrm{ml}$ of ethanol and the precipitates were washed 4 times with $1 \mathrm{ml}$ of $70 \%$ ethanol. The precipitates were then dissolved in $2 \mathrm{ml}$ of 1.0 M Hzamine and counted in a toluene based scintillation solvent.

** The amount of incorporated sugar relative to 100 moles of endogenous glucose in the LPS acceptor of the active particle.

Evidence that glucose was indeed being transferred directly to the previously added galactose residue was obtained as follows: LPS, isolated from incubation mixtures which contained the various combinations of substrates indicated in Table II, was hydrolyzed $\left(0.1 \mathrm{~N} \mathrm{H}_{2} \mathrm{SO}_{4}, 100^{\circ}\right.$, I hour) and a disaccharide was isolated from each mixture by paper chromatography first in solvent III ( $R_{G l_{c}}=0.61$ ), followed by solvent I $\left(R_{G l_{c}}=0.48\right)$. The disaccharides were reduced with $\mathrm{NaBH}_{4}$, hydrolyzed at $100^{\circ}$ for 2 hours in $2 \mathrm{~N} \mathrm{H}_{2} \mathrm{SO}_{4}$, and the labeled products characterized by paper electrophoresis in sodium molybdate buffer. An additional portion of the doubly labeled disaccharide was exhaustively hydrolyzed; the products were shown to be equimolar quantities of glucose and galactose. The results of these experiments clearly indicated that a gucosyl-galactose type of disaccharide was formed. 
Table II

\begin{tabular}{|c|c|c|}
\hline$\overline{C^{14} \text { SUBSTRATE }}$ & UNLABELED SUBSTRATE & $\begin{array}{c}C^{14} \text { PRODUCT AFTER } \\
\text { REDUCTION AND HYDROLYSIS }\end{array}$ \\
\hline UDP-galactose & UDP-glucose & Galactitol \\
\hline UDP-glucose & UDP-galactose & Glucose \\
\hline $\begin{array}{l}\text { UDP-galactose and } \\
\text { UDP-glucose }\end{array}$ & None & $\begin{array}{l}\text { Galactitol* and } \\
\text { Glucose* }\end{array}$ \\
\hline
\end{tabular}

*Equimolar quantities of each product.

Incorporation of KDO--- Preliminary experiments designed to demonstrate the enzymatically catalyzed incorporation of KDO into LPS were unsuccessful. Thus, incubation of CMP-KDO with either crude extracts or the particulate enzyme preparations (described above), with endogenous LPS or with added LPS, did not result in the transfer of KDO to the polymer. However, KDO was transferred from CMP-KDO to an acceptor prepared by partial chemical degradation of the LPS. After treatment of LPS with alkali $\left(0.2 \mathrm{~N} \mathrm{NaOH}, 60^{\circ}, 30 \mathrm{~min}\right.$.), followed by acid hydrolysis $\left(0.5 \mathrm{~N} \mathrm{HCl}, 100^{\circ}, 30 \mathrm{~min}.\right)$, a fragment was isolated which contained hexosamine, organic phosphorus and fatty acid. Addition of this material to incubation mixtures (Table III) containing CMP-KDO- $1-C^{14}$ and crude extract resulted in the incorporation of radioactivity into a product which was electrophoretically distinct from the substrate. The radioactive product was purified by a combination of paper electrophoresis (pyridinium acetate buffer) and paper chromatography (S and S Blue Ribbon, solvent 11, $R_{K D O}=1.1$ ). After elution from the paper, analysis of this material gave the following molar ratios: hexosamine, 100; organic phosphorus, 0.12; fatty acid, 0.99; KDO, 0.07 (no heptose was present). After mild acid hydrolysis of the product, all of the radioactivity was in a compound which was indistinguishable from authentic KDO by paper chromatography and paper electrophoresis. The radioactive material obtained by hydrolysis of the product was further shown to be KDO-1-C ${ }^{14}$ by its reactivity with specific KDO-aldolase (Ghalambor and Heath, 1963b); the only radioactive product of this reaction was pyruvate (determined by paper electrophoresis). The KDO was assumed to be linked glycosidically in the product on the basis of its resistance to alkaline hydrolysis, susceptibility to acid hydrolysis, and that the carbonyl group could not be reduced chemically prior to acid hydrolysis. 
Table III

\begin{tabular}{lc}
\hline INCUBATION MIXTURE & mpmoles INCORPORATED \\
\hline Complete* $^{*}$ & 0.90 \\
-acceptor & 0.10 \\
-acceptor + purified LPS & 0.13 \\
-crude extract & 0.12 \\
-CMP-KDO synthetase & 1.01 \\
-CTP & 0.45 \\
\hline
\end{tabular}

*Incubation mixtures were as follows ( $\mu$ moles): Tris, $\mathrm{pH} 8,15 ; \mathrm{MgCl}_{2}, 1$;

cytidine triphosphate, 1.25; KDO-1-C $14,0.03$; CMP-KDO synthetase, $400 \mu$; final volume, $0.075 \mathrm{ml}$. After incubation at $37^{\circ}$ for $30 \mathrm{~min} ., 0.05 \mathrm{ml}(250 \mu \mathrm{g})$ of acceptor and $0.2 \mathrm{ml}$ of crude extract were added. After incubation for $20 \mathrm{~min}$. at $37^{\circ}$, an aliquot was applied to a paper strip and subjected to electrophoresis in pyridinium acetate buffer. The radioactivity remaining at the origin was determined in a scintillation spectrometer in a tolvene solvent.

Discussion--- In contrast to LPS from the wild-type organism, the polymer from E. coli $\mathrm{J}-5$ is deficient in galactose, glucose, $\mathrm{N}$-acetyl glucosamine and colitose. The data presented in this report indicate that each of these sugars can be enzymatically transferred to the deficient LPS in an in vitro system. While the results suggest that the sugars are added sequentially ( $\mathrm{Gal}$, Glc, GlcNAc, Col) from their respective nucleotide monosaccharide derivatives, the possible involvement of nucleotide oligosaccharide intermediates has not been ruled out. Osborn and Horecker and their co-workers have demonstrated the apparent sequential enzymatic transfer of glucose, galactose, glucose and Nacetyl glucosamine to deficient LPS of a variety of mutants of Salmonella typhimurium ${ }^{7}$ (Rothfield et al., 1964; Rosen et al., 1964; Osborn and D'Ari, 1964). These sugars are apparently attached to the polyheptose phosphate "backbone" of the deficient LPS acceptor in the same order as observed in the present studies; i.e. Glc, Gal, Glc, GlcNAc. The enzymatic incorporation of galactose, rhamnose and mannose into LPS of mutants of $\underline{\mathrm{S}}$. typhimurium has also been reported (Nikaido, 1962; Nikaido and Nikaido, 1964; Zeleznick et al., 1964).

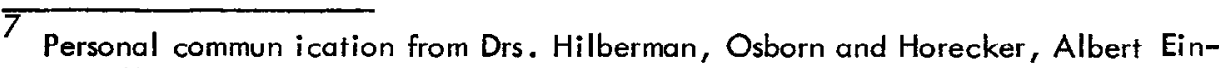
stein College of Medicine, New York, N. Y.
} 
Osborn (1963) has observed that in LPS from S. typhimurium the polyheptose phosphate "backbone" is presumably bound to KDO through the hydroxyl group at either position 7 or 8 of KDO. The apparent requirement of the degraded lipid fragment as acceptor for the enzymatic transfer of KDO from CMP-KDO suggests that at least some of the KDO in this polymer is glycosidically attached to the lipid moiety. The structure of the acceptor and the site of attachment of KDO are under investigation.

\section{References}

Boas, N. F., J. Biol. Chem., 204, 553 (1953).

Bourne, E. F., Hutson, D. H. and Weigel, H., Chem. and Ind. (London) 1047 (1959). Chen, P. S., Toribara, T. Y., and Warner, H., Anal. Chem., 28, 1756 (1956).

Doudoroff, M., In Methods in Enzymology, edited by S. P. Colowick and N. O. Kaplan, 5, 339 (1962).

Duncombe, W. G., Biochem. J., 88, 7 (1963).

Ghalambor, M. A., and Heath, E. C., Biochem. Biophys. Res. Communs., 10, 346 (1963a).

Ghalambor, M. A., and Heath, E. C., Biochem. Biophys. Res. Communs., 11, 288 (19636).

Heath, E. C. and Elbein, A. D., Proc. Nat. Acad. Sci ., 48, 1209 (1962).

Heath, E. C. and Ghalambor, M. A., Biochem. Biophys. Res. Communs., 10, 340 (1963).

Nikaido, H., Proc. Nat. Acad. Sci., 48, 1542 (1962).

Nikaido, H. and Nikaido, K., Abstracts 6th Intern. Congr. Biochem., Section VI, No. 78 (1964).

Osborn, M. J., Rosen, S. M., Rothfield, L. and Horecker, B. L., Proc. Nat. Acad. Sci., 48, 1831 (1962).

Osborn, M. J., Proc. Nat. Acad. Sci. , 50, 499 (1963).

Osborn, M. J., and D'Ari, L., Biochem. Biophys. Res. Communs., 16, 568 (1964).

Roseman, S., Distler, J. J., Moffatt, J. G. and Khorana, H. G., J. Am. Chem. Soc., 83, 659 (1961).

Rosen, S. M., Osborn, M. J., and Horecker, B. L., J. Biol. Chem., In press. Rothfield, L., Osborn, M. J., and Horecker, B. L., J. Biol. Chem., In press. Trevelyan, W. E., Procter, D. P. and Harrison, J. S., Nature, 166, 444 (1950). Waravdekar, V. S., and Saslaw, L. D., J. Biol. Chem., 234, $\overline{1945}$ (1959). Warren, L., Nature, 186, 237 (1960).

Weissbach, A., and Hurwitz, J., J. Biol. Chem., 234, 705 (1959).

Westphal, O., Luderitz, $O$ and Bister, F., Z. Naturforsch., 7b, 148 (1952).

Wiesmeyer, H. and Jordan, E., Anal. Biochem. , 2, 281 (1961).

Zeleznick, L. D., Rosen, S. M., Saltmarsh-Andrew, M., Osborn, M. J. and Horecker, B. L., Abstracts 6th Intern. Congr. Biochem., Section Vl, No. 125 (1964). 